Original Paper

Received: 29 June 2012 / Revised: 18 September 2012 / Accept: 28 September 2012

\title{
Covalent attachment of functionalized cardiolipin on a biosensor gold surface allows repetitive measurements of anti-cardiolipin antibodies in serum
}

\author{
Alice Schlichtiger ${ }^{a *}$, Claudia Baier $^{b}$, Meng-Xin Yin $^{c}$, Andrew B. Holmes ${ }^{c}, M^{2}$ Makiko Maruyama ${ }^{d}$, \\ Ralf Strasser ${ }^{d}$, Ulrich Rant ${ }^{d}$, Markus Thaler ${ }^{a}$, Peter B. Luppa ${ }^{a}$ \\ ${ }^{a}$ Institut für Klinische Chemie und Pathobiochemie, Klinikum rechts der Isar der Technischen \\ Universität München, Ismaninger Straße 22, 81675 München, Germany \\ ${ }^{b}$ Department Physik E19, Technische Universität München, James-Franck-Str. 1, 85747 Garching, \\ Germany \\ ' School of Chemistry, Bio21 Institute, Building 102, 30 Flemington Road, University of Melbourne, \\ Parkville, VIC 3010, Australia \\ d Dynamic Biosensors, c/o Walter Schottky Institut, Technische Universität München, Am \\ Coulombwall 4, 85748 Garching, Germany
}

* Corresponding author

Institut für Klinische Chemie und Pathobiochemie, Klinikum rechts der Isar der Technischen Universität München, Ismaninger Straße 22, 81675 München, Germany

Tel.: +49-89-4140-6188; Fax: +49-89-4140-4875; e-mail: schlichtiger@klinchem.med.tum.de. 


\section{Abstract}

Anti-phospholipid antibodies (aPL) are a relevant serological indicator of antiphospholipid syndrome (APS). A solid-state surface with covalently bound $\omega$-amine functionalized cardiolipin was established and the binding of $\beta 2$-glycoprotein I ( $\beta 2$-GPI) was investigated either by use of surface plasmon resonance (SPR) biosensor, by electrically switchable DNA interfaces (switchSENSE) and by scanning tunneling microscopy (STM). STM could clearly visualize the attachment of $\beta 2-$ GPI to the cardiolipin surface. Using the switchSENSE sensor, $\beta 2-$ GPI as specific ligand could be identified by increased hydrodynamic friction. The binding of anti-cardiolipin antibodies (aCL) was detected against the $\omega$-amine functionalized cardiolipin-modified SPR biosensor ( $\mathrm{aCL}$ biosensor) using sera from healthy donors, APS patients and syphilis patients. Our results showed that the aCL biosensor is a much higher sensitive diagnostic device for APS patients compared to previous methods. The specificity between $\beta 2-\mathrm{GPI}$-dependent autoimmune- and $\beta 2$-GPI-independent infection-associated types of aPLs was also studied and they can be distinguished by the different binding kinetics and patterns.

Keywords: antiphospholipid syndrome, antiphospholipid antibody, cardiolipin, $\beta 2$-glycoprotein I, phospholipid, surface plasmon resonance

Nonstandard abbreviations: $a \beta 2-G P I$, anti- $\beta 2-G P I$ antibodies; $a C L$, anticardiolipin antibody; $a P L$, antiphospholipid antibody; APS, antiphospholipid syndrome; AUC, area under the curve; BB, blocking buffer; BFP, biological false positive; $\beta 2$-GPI, $\beta 2$-glycoprotein I; FC, flow cell; FCS, fetal calf serum; HBS, HEPES-buffered saline; HRP, horseradish peroxidase; LA, lupus anticoagulant; mAb, monoclonal antibody; MW, molecular weight; PBS, phosphate buffered saline; PL, phospholipid; ROC, Receiver Operating Characteristic; RU, resonance units; SAM, self-assembled monolayer; SD, standard deviation; SLE, systemic lupus erythematosus; SPR, surface plasmon resonance; STM, scanning tunneling microscopy; TMB, 3,3',5,5'-tetramethylbenzidine; VDRL, Veneral Disease Research Laboratory; WB, washing buffer 


\section{Introduction}

Although parainfectious anti-cardiolipin antibodies $(\mathrm{aCL})$ were first described in 1906, when developing a test for syphilis [1], it took 35 years until cardiolipin was identified as the main antigenic structure [2]. This phospholipid (PL) consists of two phosphatidyl glycerols connected via a central glycerol (1,3-bis(sn-3'-phosphatidyl)-sn-glycerol). Both lateral glycerols are acylated with fatty acids via the primary and secondary hydroxyl groups. The Veneral Disease Research Laboratory (VDRL) developed a serological test using cardiolipin for mass screening to control syphilis. The application of this test identified groups of people who had positive results for syphilis without physical evidence of syphilis infection, the so called biological false positive (BFP) VDRL reactions [3]. Further, one third of patients with BFP serological tests were found to have lupus anticoagulant (LA) [4]. Today it is known that the reactivity of antibodies responsible for LA and BFP serological tests depend on protein targets that bind anionic PL such as cardiolipin, phosphatidylcholin or phosphatidyserin. Thus, the aPL from syphilis patients which directly bind to phospholipid $[5,6]$ are different from those for LA and BFP. The allocation of patterns of clinical symptoms to the laboratory finding of persistently elevated titers of aPL led to the description of the antiphospholipid syndrome (APS) [7], often also called Hughes syndrome. This autoimmune disease is characterized by a humoral hypercoagulability caused by aPL. As a result thrombosis in both, arteries and veins as well as placenta-related obstetrical complications occur. APS can develop as primary disease without association with other autoimmunities, whereas a secondary form of APS is found frequently in patients suffering from Systemic Lupus Erythematosus (SLE) or other autoimmune disorders. A minor fraction of patients with primary APS later develop SLE.. The Sydney classification criteria for APS [8] demand at least one clinical and one laboratory criterion. The latter one comprise the detection of either LA or anti-cardiolipin ( $\mathrm{aCL}$ ) or anti- $\beta 2$-glycoprotein I (aß2-GPI) antibodies and has to be confirmed by a second determination performed after 12 weeks. 
As mentioned above, aCLs in association with APS require the presence of the PL binding serum protein $\beta 2$-GPI (Figure 1a), presumably due to the involvement of $\beta 2$-GPI in immune complex formation [9-11]. This $54 \mathrm{kDa}$ single-chain serum glycoprotein binds to negatively charged PLs with high affinity [12]. During the binding event to cardiolipin, $\beta 2-$ GPI undergoes a conformational change and converts from a circular to a J-shaped structure $[13,14]$. This event presumably increases the binding capability for aPL. Nevertheless, the role of cardiolipin for the analysis of aPLs in APS patients remains a topic of controversial discussion. This is due to the observation that binding of aPLs to $\beta 2-$ GPI can also be demonstrated in the absence of cardiolipin [15-17].

In previous work it was shown that surface plasmon resonance (SPR)-based assays are auspicious tools for autoimmune diagnostics $[18,19]$. The advantage of the SPR biosensor is the real-time gathering of data concerning the association as well as the dissociation phases of antigen/antibody interactions. This enables the monitoring of the reactivity of autoantibodies in patient sera to a complementary surface-immobilized antigen.

To gain deeper insights into the role of surface-immobilized cardiolipin for the determination of aCL in APS patients, a new surface plasmon resonance (SPR)-based assay was developed. For preparation of phospholipid surfaces two main approaches have been described in the literature, the supported bilayers and immobilized bilayers or liposomes [20]. In contrast to these well described techniques where PLs are immobilized by adsorption, in this work a $\omega$-amine cardiolipin analogue 1 (Figure $1 \mathrm{~b}$ ) was immobilized covalently to a gold surface modified with self-assembled monolayer (SAM) to generate a stable and regenerative assay enabling multiple measurements.

The aims of this study were not only the development and evaluation of the aCL biosensor and its comparison with the existing aß2-GPI SPR assay [18], but also the application of two alternative sensor techniques to investigate the specific interaction of $\beta 2-$ GPI and cardiolipin which determines the performances of the both SPR assays. 


\section{Materials and Methods}

\subsection{Biochemicals}

Gold coated glass slides (SIA Kit $\mathrm{Au}$ ), the BIAcore amine coupling kit and ethanolamine- $\mathrm{HCl}$ was purchased from GE Healthcare (Freiburg, Germany). 11-mercaptoundecanoic acid, 11mercaptoundecan-1-ol, 4-(2-hydroxyethyl)-1-piperazineethanesulfonic acid (HEPES), 3,3',5,5'tetramethylbenzidine (TMB) and transferrin were obtained from Sigma-Aldrich (Taufkirchen, Germany). Potassium chloride, sodium chloride, potassium phosphate monobasic, sodium phosphate dibasic dihydrate and ethanol were purchased from Merck (Darmstadt, Germany). $\beta 2-$ GPI was from Scipac (Sittingbourne, UK). Fetal calf serum (FCS) was purchased from PAA Laboratories GmbH (Pasching, Austria).

The $\omega$-amine cardiolipin analogue 1 was synthesized by the group of Andrew B. Holmes, as previously described [21].

\subsection{Patients}

We studied 21 patients with APS, 21 healthy controls and 10 patients with positive results in the VDRL test. All APS patients satisfied the Sidney classification criteria for APS [8]. The serological parameters aCL and aß2-GPI were determined by use of the Alegria system from Orgentec (Mainz, Germany). LA was analyzed with the BCS XP from Siemens Healthcare Diagnostics (Eschborn, Germany). APS patients and controls were age-matched. The latter were assumed to be free of any acute or chronic disease on the basis of a medical and clinical chemistry examination. Each blood sample was collected in $10 \mathrm{~mL}$ tubes without anticoagulant. After clotting, the samples were centrifuged at $1500 \times \mathrm{g}$ for $15 \mathrm{~min}$. Sera were collected and stored at $-80^{\circ} \mathrm{C}$. The study was approved 
by the institutional ethics committee of the Klinikum rechts der Isar, Technische Universität München. All participants gave written informed consent. No financial compensation was provided.

\subsection{ELISA}

ELISA plates (Nunc PolySorp 96, Thermo Electron LED, Langenselbold, Germany) were coated with either cardiolipin or the $\omega$-amine functionalized cardiolipin $(50 \mu \mathrm{g} / \mathrm{mL}$ diluted in ethanol, $30 \mu \mathrm{L} /$ well) over night at $4{ }^{\circ} \mathrm{C}$. After incubation, wells were washed three times with washing buffer (WB: phosphate buffered saline (PBS); $2.6 \mathrm{mM} \mathrm{KCl}, 138 \mathrm{mM} \mathrm{NaCl}, 10 \mathrm{mM} \mathrm{HNa}{ }_{2} \mathrm{PO}_{4} * 2 \mathrm{H}_{2} \mathrm{O}, 1.8 \mathrm{mM}$ $\mathrm{H}_{2} \mathrm{KPO}_{4}, \mathrm{pH} 7.2 ; 100 \mu \mathrm{L} /$ well), blocked for $1 \mathrm{~h}$ with $200 \mu \mathrm{L} /$ well blocking buffer (BB: PBS, $10 \%$ fetal calf serum), and washed once again with WB. Serum samples were diluted 1:100 in BB and $100 \mu \mathrm{L}$ of each sample was added to wells at each dilution in duplicates and incubated for 30 min at room temperature. The wells were washed three times with WB, before $100 \mu \mathrm{l}$ of horseradish peroxidase (HRP) labeled anti-human IgG (or IgM) (Dako, Glostrup, Denmark) were added at a 1:5000 dilution in $\mathrm{BB}$, followed by incubation for $1 \mathrm{~h}$. After three times washing with $\mathrm{WB}, \mathrm{TMB}$ as substrate solution was added at $200 \mu \mathrm{L} /$ well and color was allowed to develop for $30 \mathrm{~min}$. The reaction was stopped with $\mathrm{H}_{2} \mathrm{SO}_{4}(5 \%)$ and plates were read for absorbance at $450 \mathrm{~nm}$ in an ELISA plate reader (BioTek Germany, Bad Friedrichshall, Germany).

\subsection{SPR measurements}

SPR measurements were performed using a BIAcore X (GE Healthcare) device at a working temperature of $25^{\circ} \mathrm{C}$. All measurements were performed on SIA Kit Au sensor chips (GE Healthcare). The gold surfaces were modified with a self-assembled monolayer (SAM) by incubating the surface with a $10 \mathrm{mM}$ solution of 11-mercaptoundecanoic acid and 11-mercaptoundecan-1-ol (6/4 molar ratio) in ethanol. The surface was activated by using the BIAcore amine coupling kit and HBS (HEPES- 
buffered saline; 20 mM 4-(2-hydroxyethyl)-1-piperazineethanesulfonic acid (HEPES), $500 \mathrm{mM} \mathrm{NaCl}$, $\mathrm{pH} 7.5$ ) as running buffer. After reducing the flow to $1 \mu \mathrm{L} / \mathrm{min}, 100 \mu \mathrm{L}$ of a $74 \mathrm{nM}$ solution of (-)-1-O(1'-O-[12'"-Aminododecanoyl]-2'-O-hexadecanoyl-snglycer-3'-yl-O-phosphoryl)-3-O-(1',2'-di-O-hexadecanoyl-sn-glycer-3'-yl-O-phosphoryl)-sn-glycerol diammonium salt (1) (MW: $1357 \mathrm{~g} / \mathrm{mol}$ ) in HBS were injected over the specific flow cell (FC 2). The reference cell (FC 1) was prepared under the same conditions by injecting $100 \mu \mathrm{L}$ of a $166 \mathrm{nM}$ solution of human transferrin in HBS as non-APSantigenic protein. This concentration of transferrin was chosen to ensure a complete surface coverage by the protein in order to decrease unspecific binding. Subsequently, $1.0 \mathrm{M}$ ethanolamine$\mathrm{HCl}, \mathrm{pH} 8.5$ (10 $\mathrm{min})$ was added to each flow cell to block the remaining activated carboxylic groups.

Signal differences between the two flow cells were monitored as a function of time (SPR sensorgrams), expressed in arbitrary resonance units (RU). For most macromolecules, one RU is equivalent to a change in concentration of $\sim 1 \mathrm{pg} / \mathrm{mm}^{2}$ on the sensor surface [22]. The binding of different concentrations of $\beta 2$-GPI $(1 \mu \mathrm{M}, 0.5 \mu \mathrm{M}, 0.25 \mu \mathrm{M}, 0.125 \mu \mathrm{M}, 0.0625 \mu \mathrm{M})$ was investigated at a continuous flow $(1 \mu \mathrm{L} / \mathrm{min})$ with HBS as running buffer. The surface was regenerated by a $5 \mathrm{~s}$ pulse of regeneration solution $(50 \mathrm{mM} \mathrm{NaOH}, 1 \mathrm{M} \mathrm{NaCl})$. For measuring the biomolecular interactions between the sera and the immobilized cardiolipin, a PBS-buffer $(2.6 \mathrm{mM} \mathrm{KCl}, 138 \mathrm{mM} \mathrm{NaCl}, 10 \mathrm{mM}$ $\mathrm{HNa}_{2} \mathrm{PO}_{4}{ }^{*} 2 \mathrm{H}_{2} \mathrm{O}, 1.8 \mathrm{mM} \mathrm{H}_{2} \mathrm{KPO}_{4}, \mathrm{pH}$ 7.6) with $5 \%$ of FCS was used as running buffer. The measurements were performed at a continuous flow rate of $1 \mu \mathrm{L} / \mathrm{min}$ conducting $45 \mu \mathrm{l}$ of diluted sera (1:10 with running buffer) over the surface to allow association, followed by a 300 s period of buffer injection to monitor the dissociation. After each measurement the biosensor surface was regenerated with a $5 \mathrm{~s}$ pulse of regeneration solution $(50 \mathrm{mM} \mathrm{NaOH}, 1 \mathrm{M} \mathrm{NaCl})$.

All buffers for the biosensor measurements were sterile-filtered using $0.2 \mu \mathrm{m}$ FP CA-S filters (Whatman, Dassel, Germany) and carefully degassed with helium before use. 


\subsection{Scanning tunneling microscopy (STM) measurements}

STM images were obtained either by a in-house Veeco/MI EC-STM consisting of a Nanoscope IIIA controller (Bruker AXS, Mannheim, Germany, former by Veeco Instruments) and a PicoSPM STM base (Agilent Technologies, Böblingen, Germany, former Molecular Imaging) together with an EC-Tec bipotentiostat/galvanostat BP600 and an EC-Tec bi-scangenerator SG600 or an electrochemical Veeco Multimode system with the universal bipotentiostat, a combined STM/SECPM head, a Nanoscope 3D Controller and the Nanoscope 5.31r2 software. All STM images were taken under insitu conditions in HBS in constant current mode (UBias = 100-300 mV, IT=0.2-1nA) using etched Au tips insulated with Apiezon wax. All experiments were performed in a PTFE cell with an electrolyte volume of $100-200 \mu \mathrm{l}$ and an exposed surface area of $0.13 \mathrm{~cm}^{2}$. The PTFE cell was cleaned with Caro's acid (95-98\% $\mathrm{H}_{2} \mathrm{SO}_{4}$ and $33 \% \mathrm{H}_{2} \mathrm{O}_{2}$, volume ration of $1: 1$, both Merck, pro analysi) and then thoroughly rinsed with deionized water prior to each experiment. Image processing was performed with WSxM 4.0 [23] and ImageJ [24].

The gold surface was modified with a SAM as described above. The activation of the carboxyl groups was achieved by incubation of the surface with a solution of EDC/NHS (4:1) in deionized water for 1 $\mathrm{h}$ at room temperature. After washing the surface three times with deionized water it was covered with a solution of $1(1 \mathrm{mg} / \mathrm{ml})$ in $\mathrm{HBS}$ for $12 \mathrm{~h}$ at $4{ }^{\circ} \mathrm{C}$. The surface was then washed again three times with deionized water before being covered with a solution of $\beta 2-\mathrm{GPI}(1 \mathrm{mg} / \mathrm{ml})$ in HBS for $2 \mathrm{~h}$ at room temperature. Prior to the STM image measurements the surface was washed three times with HBS.

\subsection{SwitchSENSE sensor}

Oligonucleotides obtained from IBA (Göttingen, Germany) with a mixed, non-self complementary 48 bp sequence [25] were used as switchable DNA probes. Circular gold work electrodes of $120 \mu \mathrm{m}$ 
diameter and adjacent platinum reference electrodes were deposited on glass substrates using standard metallization techniques. Double stranded DNA layers were immobilized on the gold electrodes according to a previously described protocol, which is described together with the electro-optical measurement setup in references $[25,26]$. After DNA layer preparation, the double stranded DNA layer was dehybridized by rinsing $10 \mathrm{mM} \mathrm{NaOH} \mathrm{pH} 11$ for $3 \mathrm{~min}$, and hybridized with 5' 1-modified complementary sequences. Thus, the cardiolipin moiety was located at the surfacedistal end of the DNA molecules. Carboxyl-DNA was activated by NHS/EDC and modified with the cardiolipin derivative 1. Reaction products were purified by RP-HPLC (C18 Hydrosphere). The incubation of $\beta 2$-GPI $(1 \mu \mathrm{M})$ was performed in $150 \mathrm{mM} \mathrm{NaCl}$, HEPES $20 \mathrm{mM}, \mathrm{pH} 7.3$, in stopped flow for $30 \mathrm{~min}$ at room temperature. The frequency responses of DNA switching were compared in 50 $\mathrm{mM} \mathrm{NaCl}$, HEPES (20 mM, pH 7.3).

\subsection{Statistics}

The Analyse-it ${ }^{\mathrm{TM}}$ (Analyse-it Software, Leeds, UK) add-in program for Windows Excel was used for statistical analysis. Receiver operating characteristic (ROC)-curves were plotted and areas under the curves $(A \cup C)$ as a measure of the differentiation ability ill vs. healthy were determined; $p_{0.5}$ was calculated to check whether the individual AUCs are significantly different from 0.5 [27] and $p_{c}$ whether they are significantly different from each other [28]. For ROC analysis, all 21 patients were considered to be ill even if negative in the serological analyses of aCL and aß2-GPI. Optimal cutoff values were set to yield a maximum Youden Index $(J=$ sensitivity + specificity -1$)$. For comparison of the ELISA tests, Spearman's rank correlation coefficient $r_{S}$ was determined.

\section{Results}

3.1. ELISA 
Development of a reusable biosensor for the detection of aCL requires the covalent attachment of cardiolipin to a functionalized surface. Therefore a cardiolipin derivative had to be synthesized with an amine group at the end of one of the four fatty acid side chains (Figure 1) [21]. To ensure that this synthetic derivative still retains its antigenicity, ELISA plates were coated with either cardiolipin or the $\omega$-amine functionalized derivative 1 by physiosorption. Using these assays for determination of aCL levels (IgG/IgM) in APS patients as well as in healthy controls, a comparable performance of the two compounds was observed. For the IgG-ELISAs, AUC for cardiolipin was $0.837\left(p_{0.5}<0.0001\right)$ and $0.805\left(p_{0.5}<0.0001\right)$ for 1. IgM-ELISAs yielded lower AUCs (cardiolipin: 0.697, $p_{0.5}=0.0127 ; 1: 0.658$, $\left.p_{0.5}=0.0433\right)$ than the respective IgG-ELISAs. AUCs of IgG- and IgM-ELISAs were not significantly different from each other $\left(\operatorname{IgG}: \mathrm{p}_{\mathrm{c}}=0.5914 ; \operatorname{IgM}: \mathrm{p}_{\mathrm{c}}=0.5955\right)$. The Spearman's rank correlation coefficient was $r_{S}=0.78$ for the IgG-ELISAs and $r_{S}=0.67$ for the IgM ELISAs. (ELISA data shown in the Electronic Supplementary Material, Table S1/S2).

\subsection{Immobilization of cardiolipin}

Several publications deal with carboxymethyl dextran hydrogel, modified with lipophilic $n$-alkyl chain anchors (L1 chip, Biacore) being used to capture PL vesicles in order to analyze the binding of proteins to lipid surface by surface plasmon resonance $[29,30]$. The drawback of this non-covalent immobilization strategy is the cleavage of the antigen from the surface when regenerating the chip. As a consequence, prior to every measurement the PL has to be immobilized again, leading to longer analysis time and to a lack of reproducibility of the active surface. To overcome these problems we established planar carboxyl-terminated SAM surfaces, allowing the covalent coupling of the $\omega$-amine functionalized cardiolipin 1 (Figure 2). Modification of the gold surface was visualized by STM (Figure 3). Figure 3b shows a typical STM image of the SAM modified gold surface decorated by pit-like defects, so-called vacancy islands. These pit defects were first observed by Häussling et al. [31]. Later 
it could be shown that the pits are defects in the Au surface layer, not defects in the n-alkanethiol layer [32].

\subsection{Binding of B2-GPI to immobilized cardiolipin}

We first tested the functionality of the 1-coated surface by measuring the binding of $\beta 2$-GPI. SPR sensorgrams for different $\beta 2-$ GPI concentrations $(1 \mu \mathrm{M}-0.0625 \mu \mathrm{M})$ showed clear concentration dependent signals (Figure 4a), whereas no binding events were observed to transferrin at the surface of the reference cell. For visualization, the SAM modified gold surface with immobilized 1 was incubated for $2 \mathrm{~h}$ with a solution of $\beta 2-\mathrm{GPI}(1 \mathrm{mg} / \mathrm{ml})$ in HBS and then examined by STM (Figure 4b). The surface image exhibits a dense packing of the proteins, which indicates that the surface is functionally structured, with the antigenic sites of the protein being sterically accessible for potential autoantibodies. The average size of the single proteins imaged in the STM is $100 \times 50 \times 20 \AA$ with a standard deviation (SD) of $10 \%$, which is in good accordance with the overall dimensions of the $\beta 2$ GPI molecule of $132 \times 72 \times 20 \AA[33,34]$. The measured size is slightly smaller than the crystallographic. However, one has to keep in mind that STM images always show a convolution of the surface topography and its electronic properties, such as conductivity, as well as the surface topography of the tip, especially in scanning direction. Therefore, in STM experiments the electron transfer pathway is a crucial point for mapping the topography of protein structures. If only the amide skeleton is involved in the tunneling process and not all the sidechains, the enzyme appears smaller in the STM image than it is in reality [35]. Another point that might be responsible for the mismatch of apparent morphology and crystallographic data is the fact that STMs are normally calibrated against a monoatomically high $\mathrm{Au}(111)$ step in z-direction and against the atomic structure of HOPG in $\mathrm{x}$-y-direction, not against a protein calibration standard which would be more suitable due to the different conductivity. However such calibration standards are not available. Therefore, absolute values should not be overrated. Measured dimensions only describe the 
apparent topography, which is a convolution of electronic and morphological properties. By contrast, no $\beta 2-$ GPI molecules could be detected in the STM image when incubating only the SAM modified surface with $\beta 2-\mathrm{GPI}$ under the same conditions (data shown in the Electronic Supplementary Material, Fig. S1).

For further characterization of the biospecific interaction between $\beta 2-$ GPI and 1 a new label-free technology based on electrically switchable DNA layers was applied. The advantage of the switchSENSE sensor is the possibility not only to detect the binding event but also to estimate the molecular size of bound ligand molecules. The probes are short (48 bp) DNA molecules which are tethered at one end to gold microelectrodes on a chip. The DNAs' top ends are modified with receptors, in this case cardiolipin. By applying alternating electric voltages to the electrodes, the charged DNA molecules are dynamically switched between an upright and a reclined conformation, as indicated schematically in Figure 5a. This conformational switching process is monitored in realtime mode by the fluorescence signals emitted from dyes attached to the DNA top ends (Figure 5b). The DNA switching can be driven at frequencies exceeding $100 \mathrm{kHz}$, however DNA velocity is limited by hydrodynamic friction damping the oscillation amplitude $\Delta \mathrm{F}$ (Figure $5 \mathrm{~b}$ ) at high frequencies. The maximum achievable DNA velocity can be characterized by the cut-off frequency $f_{c}$ being defined as the frequency value for which the switching amplitude $\Delta \mathrm{F}$ has decreased to $50 \%$ of its lowfrequency value [25]. The cut-off frequency of a DNA layer modified with 1 as receptor is $f_{c}=172$ $\mathrm{kHz}$. After incubation with $\beta 2-\mathrm{GPI}(1 \mu \mathrm{M})$ as ligand for cardiolipin in $\mathrm{HBS}$, a pronounced decrease of $f_{c}$ by $-17 \mathrm{kHz}$ can be observed which corresponds to a slowdown of the switching dynamics by app. 10 \%. By contrast, the cardiolipin-negative control layer does not show any response. The $17 \mathrm{kHz}$ frequency shift can be attributed to an increase in hydrodynamic friction due to the binding of $\beta 2$ GPI to 1-modified DNA. By comparison with previous measurements in which the frequency shift was experimentally determined for proteins of different molecular weight [25], the added molecular weight at the 1-modified DNA end can be estimated to be $\sim 50 \mathrm{kDa}$. This is in agreement with the 
expected MW of $\beta 2-$ GPI. Hence, the results obtained by the switchSENSE method confirm the binding of $\beta 2$-GPI to the $\omega$-amine-functionalized cardiolipin 1.

\subsection{SPR biosensor analysis of APS-patient sera}

Healthy donors showed no aCL-specific activity under optimized SPR sensor conditions (see above). The maximum binding signals after injection of diluted sera $(1: 10)$ of healthy donors with negative syphilis serology under appropriate experimental conditions (PBS with $5 \%$ FCS) was as small as 126 $\mathrm{RU}$, whereas sera of aCL ELISA-positive APS patients showed values in the broad range of $266-1748$ $\mathrm{RU}$ (Figure 6a). It is known that the titres of aCL positive APS patient extend over a broad range [18]. By setting a cutoff value of $126 \mathrm{RU}$ (Youden Index $=1$ ) [36], we were able to detect aCL in patient sera with confirmed APS with $100 \%$ diagnostic specificity and $100 \%$ sensitivity. Analyzing the same set of sera in a routine aCL IgG/IgM ELISA (Orgentec, Germany), the APS patients were detected with $100 \%$ specificity at a sensitivity of $85.7 \%$. Hence, the developed biosensor is more sensitive in comparison with the standard ELISA tests used in routine diagnostics. Reproducibility was assessed on 3 separate biosensor chips by performing multiple injections of a single APS serum with CL IgG ELISA titers of $>120 \mathrm{U} / \mathrm{ml}$ in the routine ELISA. Each sensor surface was stable for 15 measurements with a SD of $3.6 \%$ for the maximum binding measured at the end of the association. Chip-to-chip reproducibility has a SD of $2.6 \%$. (SPR data are shown in the Electronic Supplementary Material, Fig. S2/S3).

A primary problem using cardiolipin as the antigen in immunoassays for APS is the presence of parainfectious aCL. Therefore we also tested sera from syphilis patients with positive VDRL test in the SPR biosensor and, as it was observed in the ELISA, a significant binding to cardiolipin could be detected (Figure 6b). 
In contrast to the ELISA which does not allow reliable differentiation of affinity and avidity of antibody binding, the SPR biosensor device allows resolution of association and dissociation phases to monitor the reactivity of antibodies in patient sera to surface-immobilized cardiolipin. We could show that it may be possible to distinguish patients with APS and syphilis by assessing the profile of the binding curve (Figure 6): The aCL found in APS patient sera showed a higher association rate, whereas the ascending dissociation curves of the $\mathrm{aCL}$ from VDRL positive sera point to rebinding phenomena often seen in low affine IgM antibodies. Comparing the ratios of the resonance units at the beginning of dissociation ( $285 \mathrm{~s}$ ) and after a dissociation phase of 100 seconds ( $385 \mathrm{~s}$ ), the values for APS patients are lower than $100 \%$, whereas for patients with syphilis the values are higher than $100 \%$ (data shown in the Electronic Supplementary Material, Fig. S4). This points to the predominance of a highly refined IgG autoantibody type in APS.

\section{5. aCL biosensor vs. ab2-GPI biosensor}

Previously we reported the development of a SPR biosensor for the detection of aß2-GPIs in APS patient serum [18]. Although we were able to detect the respective autoantibodies against immobilized $\beta 2-\mathrm{GPI}$, further experiments showed that the assay performance strongly depends on the $32-$ GPI preparation used [37]. The same set of patient and healthy control sera tested in the aCL SPR system presented herein were also investigated with the aß2-GPI assay. As in the aCL SPR assay, sera of healthy controls showed no binding to the surface-immobilized $\beta 2$-GPI (Figure 6c). When applying a cutoff value of $17 \mathrm{RU}$ (Youden Index $=0.49$ ), the APS patients were detected with $96.8 \%$ specificity at a sensitivity of $52.4 \%$. As shown in prior work, VDRL positive patients showed no binding to the aß2-GPI biosensor [18]. 


\section{Discussion}

The specific interaction of $\beta 2$-GPI with surface-immobilized $\omega$-amine cardiolipin was investigated using two different biosensor approaches (SPR and a switchable DNA layer sensor) and visualized by STM. Additionally, the functionalized surface employed in a SPR biosensor system allowed the detection of $\mathrm{aCL}$ in APS-affected patient sera. The results were compared with routine ELISA tests as well as with the aß2-GPI biosensor previously reported [18].

In contrast to established analytical methods, the label free SPR technique allows monitoring of antigen-antibody interactions in real time. The pivotal step in the development of regenerative solidstate biosensor surfaces is the covalent immobilization of the antigen (cardiolipin) on the gold support. As the native structure of cardiolipin contains no suitable functional group for covalent immobilization, it must be functionalized by chemical synthesis [21]. The amine group introduced at the end of one of the fatty acids (substance 1) allowed directed covalent immobilization on the carboxyl groups of the SAM modified gold surface (Figure 2). Changing the molecular structure of a substance, however, can affect biological characteristics. To ensure that the modification did not affect the biological activity of 1, the performance was tested in an aCL ELISA and compared with the ELISA using unmodified cardiolipin as the antigen. Statistical analysis revealed no significant difference in the diagnostic efficiency between the assays. This proved that the functionalization did not impair the biological function of the $\omega$-amine cardiolipin analogue.

Besides a potentially altered molecular structure, the covalent surface immobilization can also affect the antigenic characteristics of the PL. STM and switchSENSE were used for characterization of the chip surface and for investigation of the binding of $\beta 2$-GPI to the immobilized cardiolipin. STM allows the imaging of surfaces down to a single-molecule level. The modification of the gold surface by SAM as well as the bound $\beta 2$-GPI on the covalently immobilized 1 could successfully be visualized (Figure 3, 4b). Furthermore the switchSENSE technology based on electrically switchable DNA layers was 
used not only to detect the binding event but also to estimate the molecule weight of the bound target ligand $[25,26]$. The observed shift of the frequency signal after incubation with a solution of $\beta 2-\mathrm{GPI}$ corresponded to a mass change of $\sim 50 \mathrm{kDa}$, the MW of $\beta 2-\mathrm{GPI}$ (Figure 5). Measuring the binding of $\beta 2-$ GPI to cardiolipin at different concentrations with SPR, the sensorgrams showed a clear concentration dependency (Figure 4a), whereas no binding was observed to transferrin on the reference cell. From these results it can be concluded that the 1-modified surface is suitable for detecting the specific binding of $\beta 2-\mathrm{GPI}$ in a concentration dependent manner.

An important demand for the aCL SPR biosensor is the ability to differentiate sera from APS patients and healthy control subjects. The use of a cutoff value of $126 \mathrm{RU}$ in the SPR biosensor assay offered high specificity (100\%) at equaly high sensitivity. In comparison the ELISA used in routine showed same specificity but was less sensitive (85.7\%). Additionally, the behavior of sera from syphilis patients in our assay was examined. As expected we could observe positive results for all these sera. As the biosensor allows resolution of association and dissociation phases we speculate that it might be possible to discriminate between the different diseases on the basis of the shapes of the binding curves, which were caused by different binding kinetics. This phenomenon can be explained by the fact, that aPLs in APS belong to $\beta 2-G P I-d e p e n d e n t$ autoimmune-, whereas aPLs in syphilis belong to B2-GPI-independent infection-associated types [38,39].

We previously developed a SPR biosensor for the detection of aß2-GPI antibodies [18]. Testing the sera of the same patients (APS and syphilis) and healthy controls in this study, the aß2-GPI assay was less sensitive (52.4\%) in comparison to the aCL SPR assay. In both assays $\beta 2-G P I$ is the main antigenic substance, but binding to surface-immobilized 1 allows optimal orientation of $\beta 2$-GPI to be recognized by aPLs. The higher sensitivity of the aCL SPR assay is therefore conclusive. Cardiolipin, however, is not only involved as the antigenic structure in APS but also in many other diseases with parainfectious aPL (e.g., infection with parvovirus B19) $[40,41]$ making the aCL method less specific. 
Only the combination of the chips for $\mathrm{a} \beta 2-\mathrm{GPI}$ and $\mathrm{aCL}$ achieves the clinically required sensitivity and specificity for the detection of aPL in APS patient sera.

\section{Conclusion}

In summary, switchSENSE and STM functionally revealed that $\omega$-amine cardiolipin modified surface was suitable for detecting the specific binding of $\beta 2-$ GPI. It can also be demonstrated that the SPR biosensor with covalent attached functionalized cardiolipin was a suitable method for aPL measurements in patient sera. This biosensor-based analytical assay system offers relevant diagnostic advantages compared with conventional ELISA formats. It shows higher sensitivity and additionally allows analysis of binding kinetics and affinities. The latter data may enable differentiation between APS and other diseases where parainfectious aPLs are involved as well. This overcomes the drawback of lower specificity when using $\mathrm{aCL}$ in comparison to aß2-GPI assays leading to a highly sensitive and specific diagnostic approach for APS.

\section{Acknowledgments}

The authors thank Anita Schreiegg for excellent technical assistance. This study was supported by the Stiftung Pathobiochemie und Molekulare Diagnostik of the German Society of Clinical Chemistry and Laboratory Medicine and the Australian Research Council, Discovery Project, Grant DP1094497.

\section{References}

1. Wassermann A, Neisser A, Bruck C (1906) Dtsch Med Wochenschr 32:745-746

2. Pangborn MC (1941) Proceedings of the Society for Experimental Biology and Medicine 48:484486

3. Moore JE, Mohr CF (1952) J Am Med Assoc 150:467-473

4. Johansson EA, Lassus A (1974) Ann Clin Res 6:105-108

5. Arnout J, Meijer P, Vermylen J (1999) Thromb Haemost 81:929-934 
6. Celli CM, Gharavi AE, Chaimovich H (1999) Biochim Biophys Acta 1416:225-238

7. Hughes GR (1983) Br Med J (Clin Res Ed) 287:1088-1089

8. Miyakis S, Lockshin MD, Atsumi T, Branch DW, Brey RL, Cervera R, Derksen RH, PG DEG, Koike T, Meroni PL, Reber G, Shoenfeld Y, Tincani A, Vlachoyiannopoulos PG, Krilis SA (2006) J Thromb Haemost 4:295-306

9. McNeil HP, Simpson RJ, Chesterman CN, Krilis SA (1990) Proc Natl Acad Sci U S A 87:4120-4124

10. Galli M, Comfurius P, Maassen C, Hemker HC, de Baets MH, van Breda-Vriesman PJ, Barbui T, Zwaal RF, Bevers EM (1990) Lancet 335:1544-1547

11. Matsuura E, Igarashi Y, Fujimoto M, Ichikawa K, Koike T (1990) Lancet 336:177-178

12. von Landenberg P, von Landenberg C, Schölmerich J, Lackner KJ (2001) Med Klin (Munich) 96:331-342

13. Wang SX, Cai G, Sui S (1999) Biochemistry 38:9477-9484

14. Wang SX, Sun YT, Sui SF (2000) Biochem J 348 Pt 1:103-106

15. Arvieux J, Roussel B, Jacob MC, Colomb MG (1991) J Immunol Methods 143:223-229

16. Cabral AR, Cabiedes J, Alarcon-Segovia D (1995) J Rheumatol 22:1894-1898

17. Keeling DM, Wilson AJ, Mackie IJ, Machin SJ, Isenberg DA (1992) Br J Haematol 82:571-574

18. Metzger J, von Landenberg P, Kehrel M, Buhl A, Lackner KJ, Luppa PB (2007) Clin Chem 53:11371143

19. Buhl A, Page S, Heegaard NH, von Landenberg P, Luppa PB (2009) Biosens Bioelectron 25:198203

20. Beseničar M, Maček P, Lakey JH, Anderluh G (2006) Chemistry and Physics of Lipids 141:169-178

21. Johns MK, Yin MX, Conway SJ, Robinson DE, Wong LS, Bamert R, Wettenhall RE, Holmes AB (2009) Org Biomol Chem 7:3691-3697

22. Stenberg E, Persson B, Roos H, Urbaniczky C (1991) Journal of Colloid and Interface Science 143:513-526

23. Horcas I, Fernandez R, Gomez-Rodriguez JM, Colchero J, Gomez-Herrero J, Baro AM (2007) Rev Sci Instrum 78:013705

24. Rasband WS, ImageJ (1997-2008) U.S. National Institutes of Health, Bethesda, Maryland, USA. http://rsb.info.nih.gov/ij/ Accessed 28.06.2012

25. Rant U, Pringsheim E, Kaiser W, Arinaga K, Knezevic J, Tornow M, Fujita S, Yokoyama N, Abstreiter G (2009) Nano Lett 9:1290-1295

26. Rant U, Arinaga K, Scherer S, Pringsheim E, Fujita S, Yokoyama N, Tornow M, Abstreiter G (2007) Proc Natl Acad Sci U S A 104:17364-17369

27. Hanley JA, McNeil BJ (1982) Radiology 143:29-36

28. DeLong ER, DeLong DM, Clarke-Pearson DL (1988) Biometrics 44:837-845

29. Gamsjaeger R, Johs A, Gries A, Gruber HJ, Romanin C, Prassl R, Hinterdorfer P (2005) Biochem J 389:665-673

30. Krugmann S, Anderson KE, Ridley SH, Risso N, McGregor A, Coadwell J, Davidson K, Eguinoa A, Ellson CD, Lipp P, Manifava M, Ktistakis N, Painter G, Thuring JW, Cooper MA, Lim ZY, Holmes AB, 
Dove SK, Michell RH, Grewal A, Nazarian A, Erdjument-Bromage H, Tempst P, Stephens LR, Hawkins PT (2002) Mol Cell 9:95-108

31. Häussling L, Michel B, Ringsdorf H, Rohrer H (1991) Angewandte Chemie International Edition in English 30:569-572

32. Edinger K, Goelzhaeuser A, Demota K, Woell C, Grunze M (1993) Langmuir 9:4-8

33. Bouma B, de Groot PG, van den Elsen JM, Ravelli RB, Schouten A, Simmelink MJ, Derksen RH, Kroon J, Gros P (1999) EMBO J 18:5166-5174

34. Schwarzenbacher R, Zeth K, Diederichs K, Gries A, Kostner GM, Laggner P, Prassl R (1999) EMBO J 18:6228-6239

35. Albrecht T (2003) Dynamik und Mechanismen der heterogenen Elektronentransferprozesse von synthetischen und natürlichen Haemproteinen. Technische Universität Berlin, Berlin

36. Fluss R, Faraggi D, Reiser B (2005) Biometrical Journal 47:458-472

37. Müller C, Schlichtiger A, Balling G, Steigerwald U, Luppa PB, Thaler M (2010) Thromb Res 126:e102-109

38. Matsuda J, Saitoh N, Gohchi K, Gotoh M, Tsukamoto M (1993) Br J Haematol 85:799-802

39. Petrovas C, Vlachoyiannopoulos PG, Kordossis T, Moutsopoulos HM (1999) J Autoimmun 13:347355

40. Chou TN, Hsu TC, Chen RM, Lin LI, Tsay GJ (2000) Lupus 9:551-554

41. Hsu TC, Tsay GJ (2001) Rheumatology (Oxford) 40:152-157 


\section{Figures}

Fig. 1 Structures of the two main antigens used for the SPR-Assays: a: $\beta 2$-glycoprotein I; b: $\omega$-amine functionalized cardiolipin 1 [21]

Fig. 2 Covalent immobilization of antigens on a SAM modified gold surface

Fig. 3 Successful modification of the gold surface with a self assembled monolayer imaged by STM. a: blank gold surface; b: gold surface after $12 \mathrm{~h}$ incubation with a $10 \mathrm{mM}$ solution of 11mercaptoundecanoic acid and 11-mercaptoundecan-1-ol (ratio: 6/4) in ethanol

Fig. 4 a: Sensorgrams of the aCL SPR biosensor for different concentrations of $\beta 2-G P I(1 \mu M, 0.5 \mu M$, $0.25 \mu \mathrm{M}, 0.125 \mu \mathrm{M}, 0.0625 \mu \mathrm{M}) ; \mathrm{b}: \mathrm{STM}$ imaging of the SAM/1 surface after incubation with $\beta 2-\mathrm{GPI}$

Fig. 5 Detection of $\beta 2-$ GPI by the switchSENSE sensor. a: Schematic illustration of electrically switchable DNA molecules, oscillating in an applied ac field. The DNA top end is modified with a fluorescence dye (Су3) for detection, and with $\mathrm{CL}$ receptors for $\beta 2-\mathrm{GPI}$ binding. b: Electric potential (top panel) applied to gold microelectrodes and Cy3 fluorescence emission (bottom panel) from the switching DNA layer. The fluorescence is high when the DNA stands and low when the DNA lies on the surface, because the Cy3 emission is quenched in proximity of the gold. c: Maximally attainable switching frequency (cut-off frequency fc) for CL-modified DNA layers and reference DNA layers without $\mathrm{CL}$ before and after the incubation with $\beta 2-\mathrm{GPI}$. Column heights are normalized to $f_{c, \text { before }}$ values, numbers denote the measured $f_{c}$ values

Fig. 6 SPR analysis. a: aCL SPR assay of APS patients (orange) and healthy controls (blue); b: aCL SPR assay of VDRL positive patients (green) and healthy controls (blue); c: aß2-GPI assay of APS patients 
(orange) and healthy controls (blue); D: a $32-$ GPI assay of VDRL positive patients (green) and healthy controls (blue) 
a<smiles>c1ccc(CSc2ccccc2)cc1</smiles>

b

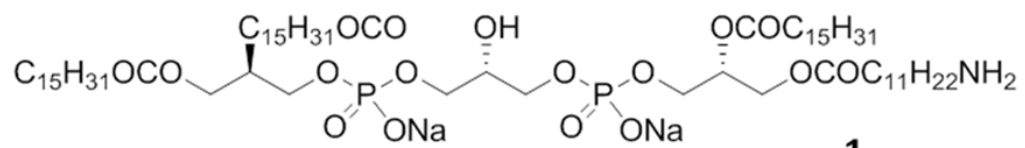

$\underline{1}$

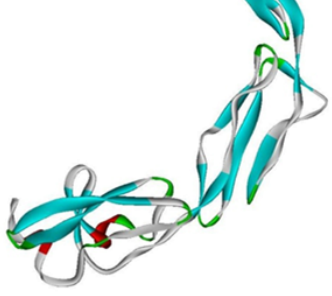




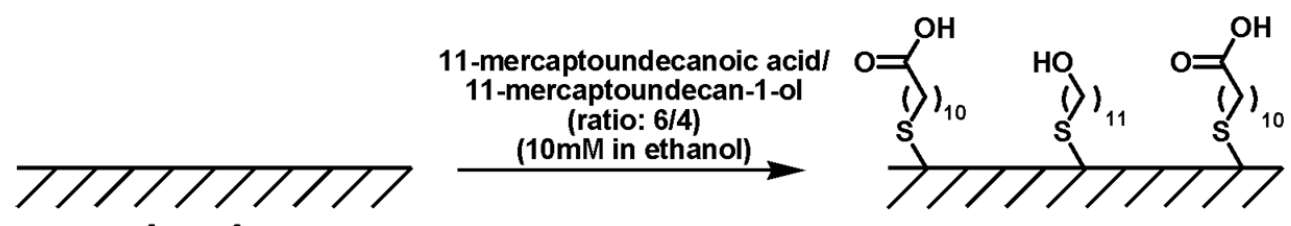

Au surface
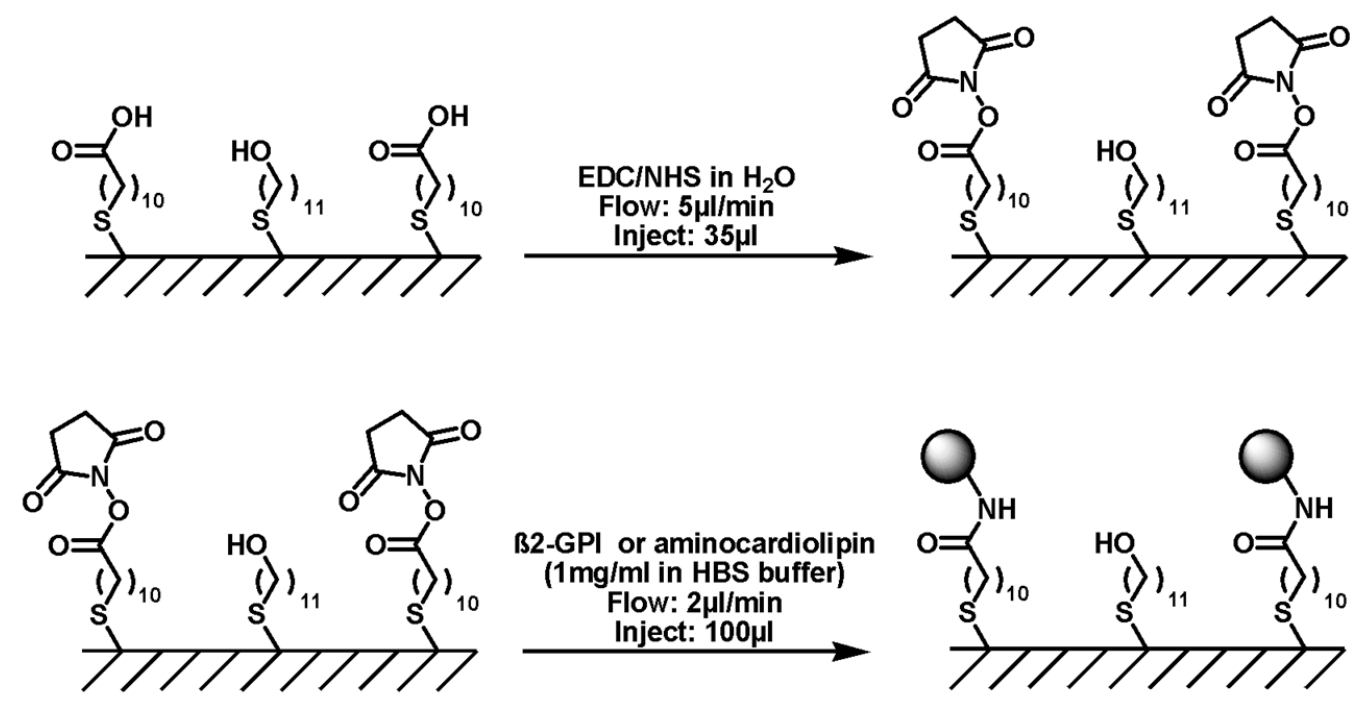

B2-GPI or aminocardiolipin (1 $\mathrm{mg} / \mathrm{ml}$ in HBS buffer)

Flow: $2 \mu \mathrm{l} / \mathrm{min}$ Inject: $100 \mu l$

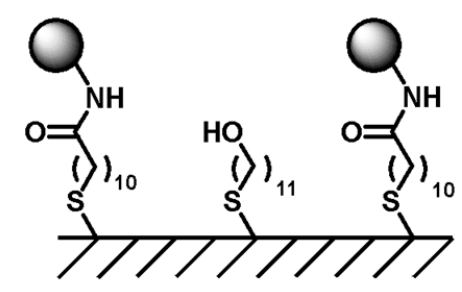

$Q=$ B2-GPI or cardiolipin 


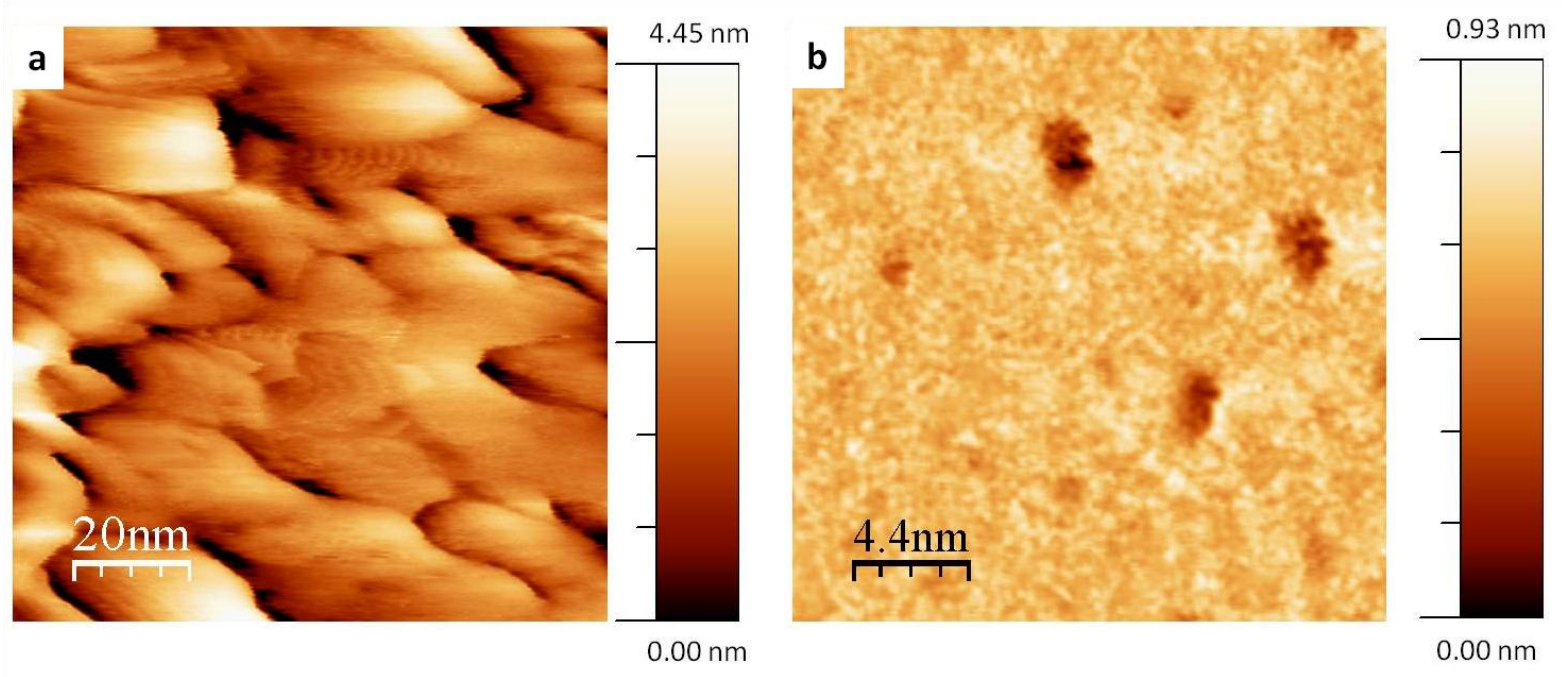




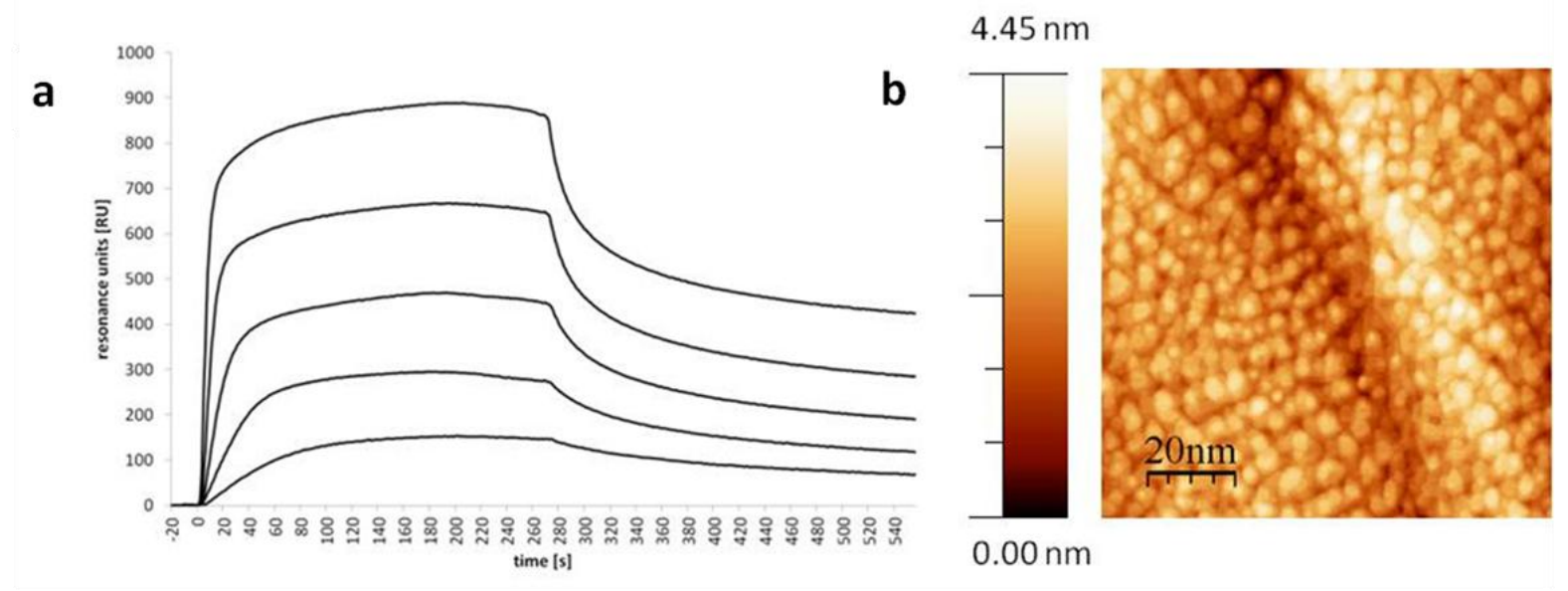



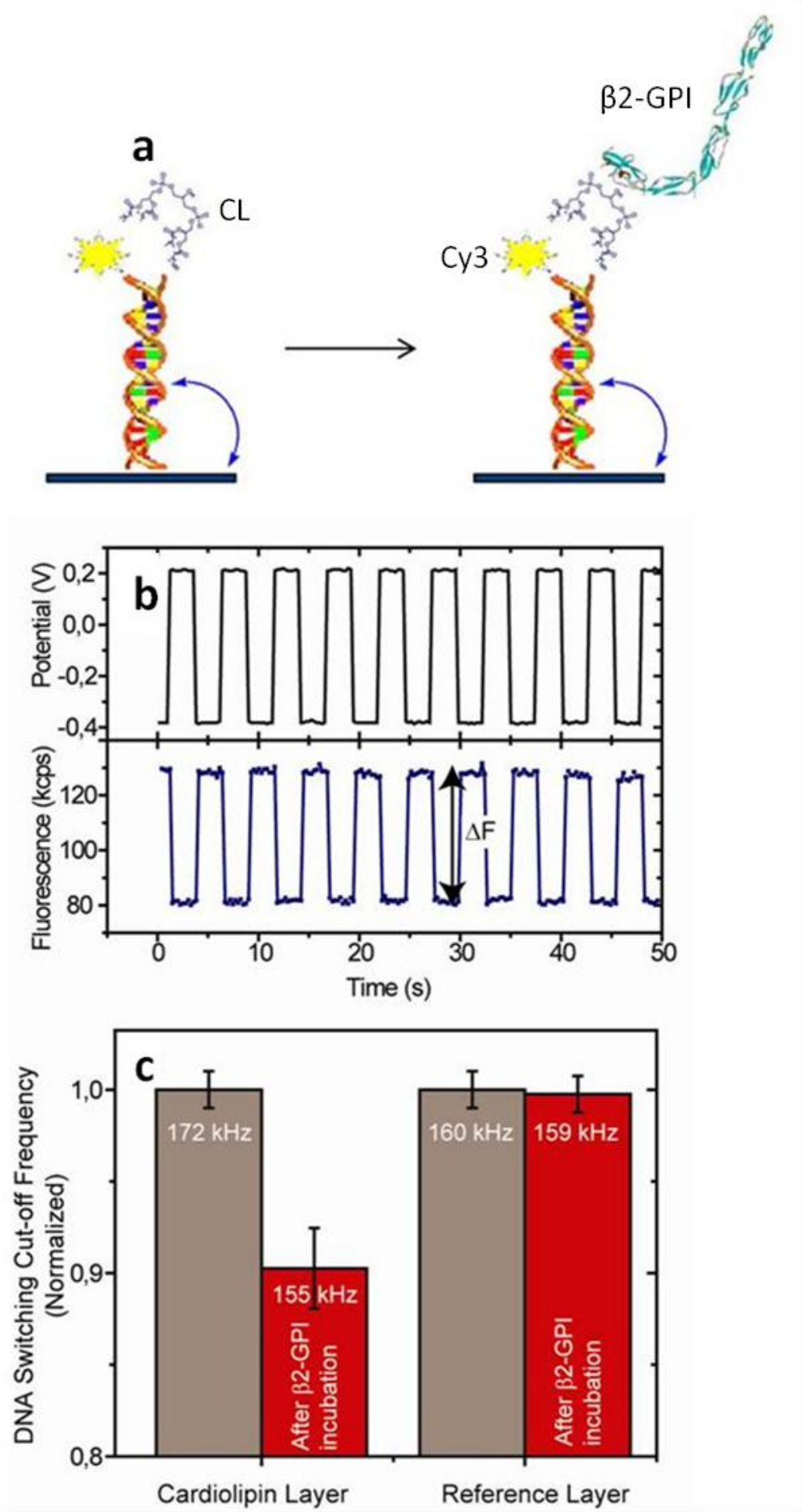

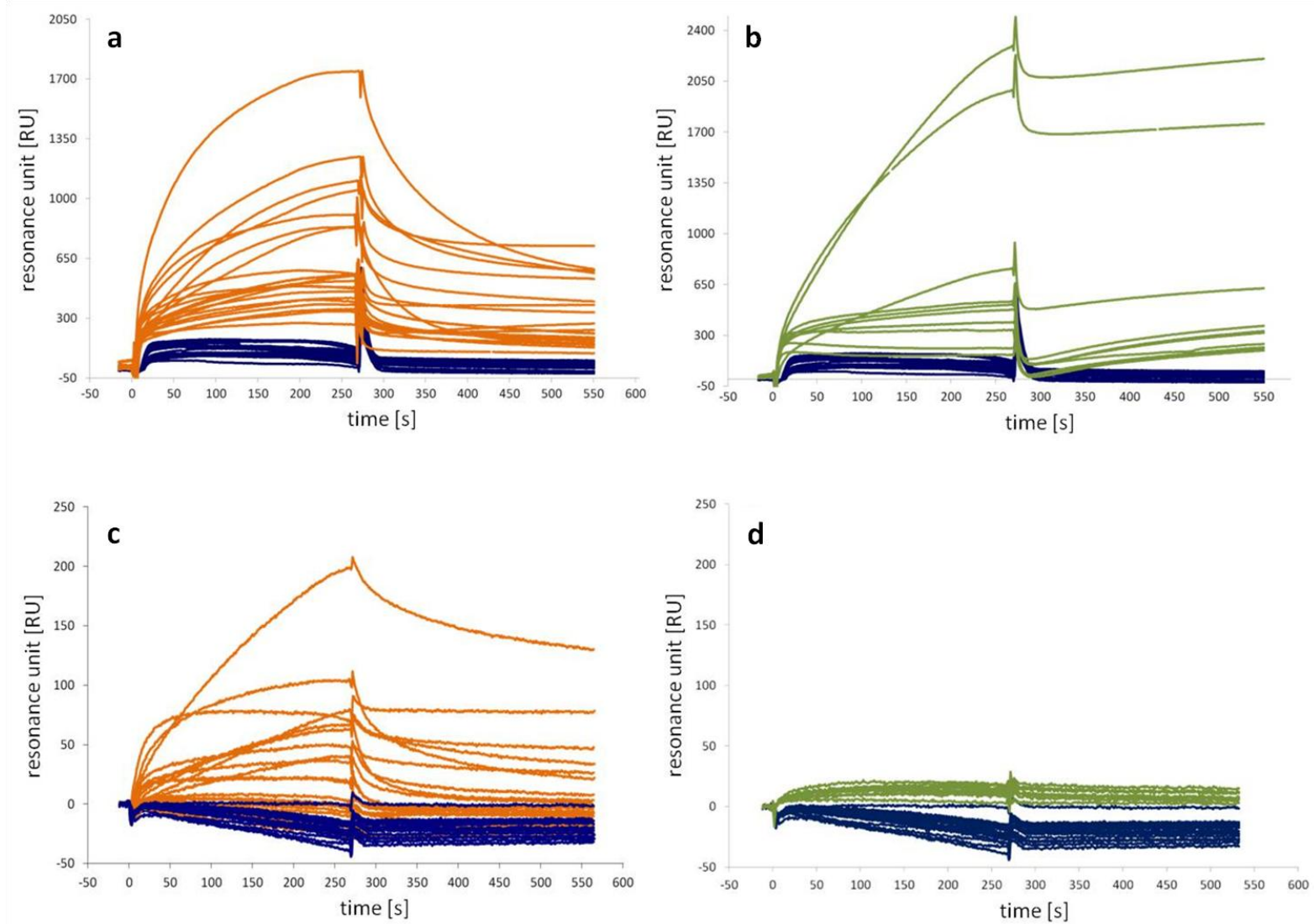


\section{University Library}

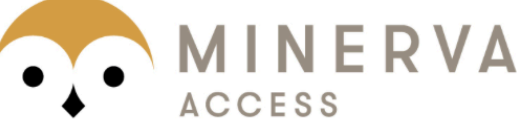

A gateway to Melbourne's research publications

Minerva Access is the Institutional Repository of The University of Melbourne

Author/s:

Schlichtiger, A;Baier, C;Yin, M-X;Holmes, AB;Maruyama, M;Strasser, R;Rant, U;Thaler, M;Luppa, PB

Title:

Covalent attachment of functionalized cardiolipin on a biosensor gold surface allows repetitive measurements of anticardiolipin antibodies in serum

Date:

2013-01-01

Citation:

Schlichtiger, A., Baier, C., Yin, M. -X., Holmes, A. B., Maruyama, M., Strasser, R., Rant, U., Thaler, M. \& Luppa, P. B. (2013). Covalent attachment of functionalized cardiolipin on a biosensor gold surface allows repetitive measurements of anticardiolipin antibodies in serum. ANALYTICAL AND BIOANALYTICAL CHEMISTRY, 405 (1), pp.275-285. https:// doi.org/10.1007/s00216-012-6467-8.

Persistent Link:

http://hdl.handle.net/11343/283182 